\title{
Geomagnetic reversal paths
}

SIR - New palaeomagnetic records of the transitional fields during geomagnetic reversals are bringing about a radical revision of ideas on the morphology of these fields. Recently, we and others have reported many new reversal records, a remarkable preponderance of which show the position of the virtual geomagnetic pole (VGP) moving along the longitude of the Americas or its antipode ${ }^{1,2}$ as the reversal proceeds ( $a$ in the figure). The VGP is by convention the south magnetic pole of the dipole field that would give the observed declination and inclination at a site; hence, comparison of VGP paths from different sites yields information on the morphology of the field. The records include reversals ranging from $100,000 \mathrm{yr}$ to at least $10 \mathrm{Myr}$ in age; the persistence of the observed pattern may therefore reflect inherent characteristics of the geodynamo.

Here we point out that the same bands of longitude picked out by the transitional VGP paths prove to be important in other geophysical observations. For example, they have
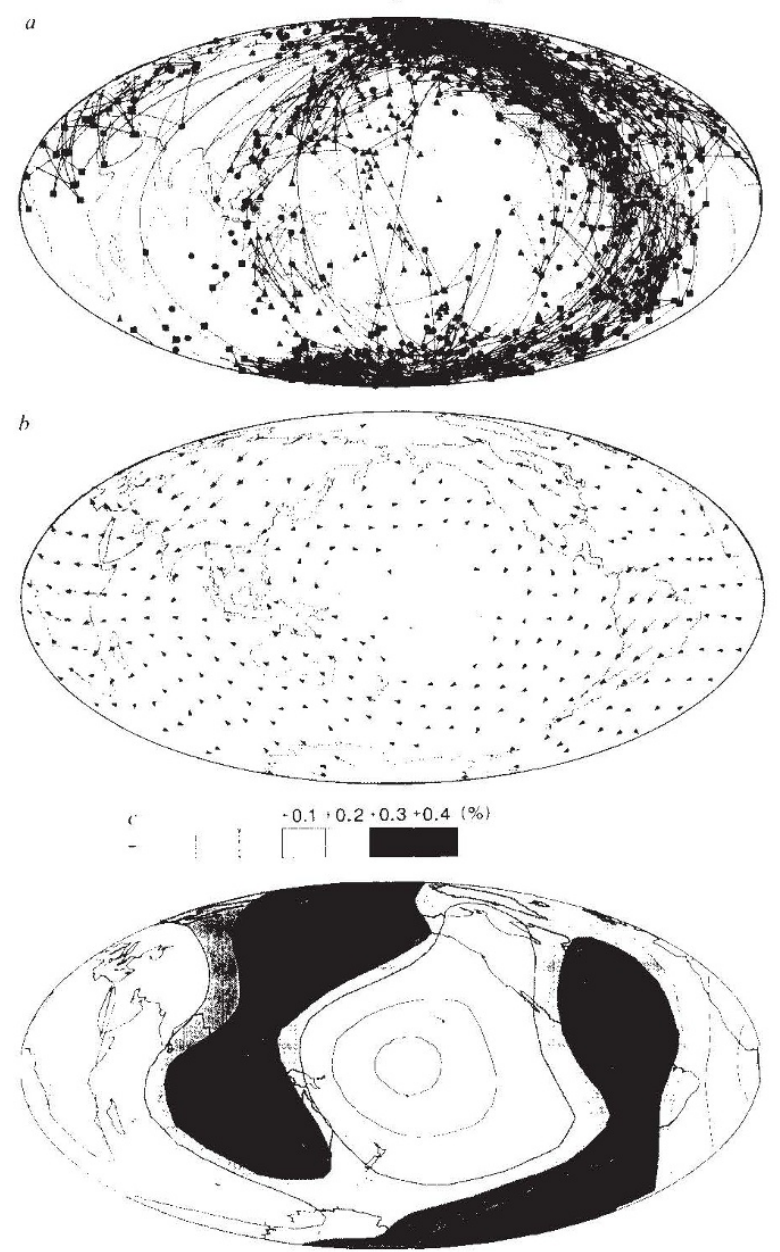

a, VGP trajectories for the Blake event $(115,000-120,000$ yr before present), the Upper Olduvai reversal, ( 1.8 Myr) and two reversals at $\sim 6.5$ and $\sim 11$ Myr. $b$, Fluid motion at the top of the core (from ref. 3). c, Seismic P-wave velocity of the lower mantle, at a depth of $2,300 \mathrm{~km}$ (adapted from ref. 6 ). Velocities given as deviations from the mean. (See cover for colour version.) be. For example, does some of the radial flux get swept into the toroidal flow? Do the flux bundles remain antipodal during the reversal? We think that it is not simply a coincidence that the longitudes of north-south core flow are those preferred by the VGP paths.

The link between reversal paths, the present magnetic field, flow in the core and temperature in the mantle, if confirmed by further work, will have profound implications. Because the time constants of mantle convection are orders of magnitude longer than those of the core, the persistence of the VGP bands over tens of millions of years suggests that fluid flow in the core is controlled, or at least modulated, by the temperature at the core/mantle boundary, which is determined by the pattern of mantle convection ${ }^{5}$. Thus, the engine of the planet appears to manifest itself in related internal motions from the core to the lithosphere, and geomagnetic phenomena in the core are ultimately related to plate tectonics.

Carlo Laj

Alain Mazaud

RoBin WeEkS

Centre des Faibles Radioactivités,

Laboratoire Mixte CEA-CNRS,

91198 Gif-sur-Yvette, France

MIKE FULLER

Department of Geological Sciences,

University of California,

Santa Barbara, California 93016, USA

Emilio Herrero-Bervera possibilities. As the poles of the dipole field are the foci of radial flux lines entering and emerging from the core, the VGP paths during reversals should tell us something about the behaviour of the flux bundles. The flux bundles are reduced in strength compared with times when the field is not reversing, but the VGP paths suggest that some vestige remains throughout the reversal. Given the core flow pattern, it seems likely that flux bundles will, at least initially, move towards the Equator at those longitudes where there is flow towards the Equator. Similarly, during the recovery phase, flux bundles should be transported poleward at longitudes where there is poleward flow. The longitudes of north-south flow are at $90^{\circ} \mathrm{W}$ and $90^{\circ} \mathrm{E}$, which are indeed the preferred longitudes of the VGP paths.

The degree to which the field is dipolar during the reversal, or displays some more complicated geometry, with paths dependent on the observation site, will depend on the details of the radial flux bundles. It is not at all clear how intact the flux bundles will remain, nor how important diffusion will
Hawaii Institute of Geophysics,

University of Hawaii,

Honolulu, Hawaii 96822, USA

1. Tric, E. etal. Phys. Earth planet. Inter. 65, 319-336(1991)

2. Clement. B. M. \& Kent, D. V. Geophys. Res. Lett. 18, 81-84

3. Bloxham, J. \& Jackson, A. Rev. Geophys. 29, 97-120 (1991).

4. Olson, P., Silver, P. G. \& Carlson, R. W. Nature 344 209-215 (1990).

5. Gubbins, D. \& Bloxham, J. Nature 325, 509-512 (1987) 6. Dziewonski, A. M. \& Woodhouse, J. H. Science 236, 37-48 (1987).

\section{Triple helix stabilization?}

$\mathrm{S}_{\mathrm{IR}}-$ There is an error in the interpretation of the data in the recent paper by Reaban and Griffin ${ }^{1}$. They demonstrate that when a plasmid containing a 2.3-kb segment of $\operatorname{IgA}$ switch tandem repeats is transcribed in vitro in the same direction as it is in vivo, the synthesized RNA forms a heteroduplex with the plasmid DNA, which results in a reduction of the supercoiling of the plasmid. This does not occur when the same sequences are transcribed in the antisense direction.

The authors interpret this to suggest that the switch sequence forms a triple-stranded DNA structure, which is stabilized by the RNA. But the RNA transcribed in this direction from the plasmid and also in vivo would be purine-rich, and not pyrimidine-rich, as they suggest, and therefore would probably 
not stabilize a triple-stranded DNA structure, as this plasmid has been shown to form a triple-stranded structure consisting of one purine strand and two pyrimidine strands, with the free single-strand being the purine strand?

This error does not diminish the value of the observation ', as the finding of a heteroduplex and altered conformation of the DNA in the transcribed plasmid suggests a hypothesis for how transcripts from unrearranged heavy-chain constant-region genes could direct switch recombination.

Janet Stavnezer

Department of Molecular Genetics, and Microbiology,

University of Massachusetts Medical School,

55 Lake Avenue North, Worcester, Massachusetts 01605, USA

Reaban ANd GRIFin REPI.y - Further DNA sequence analysis of the plasmid pBS- $\alpha$ S2.3 confirms Stavnezer's observation that transcription by T7 RNA polymerase would produce a transcript containing the polypurine sequence (AGGAG) ( $2 x$, rather than the polypyrimidine transcript reported in our manuscript ${ }^{1}$. We regret this error in our data.

But the fact that the $\mathbf{T} 7$ transcript is purine-rich would not exclude it from stabilizing an intramolecular DNA triplex. Under our transcription conditions $\left(8 \mathrm{mM} \mathrm{MgCl}_{2}\right.$ and $\mathrm{pH} 8.0$ ) a purine-purine-pyrimidine intramolecular DNA triplex is likely to form. This triplex would be stabilized by basepairing with the purine-rich $\mathrm{T} 7$ transcript via its excluded pyrimidine strand. A poly $(\mathrm{dG})-\operatorname{poly}(\mathrm{dC})$ sequence has been shown to form either a poly $(\mathrm{dG})-\operatorname{poly}(\mathrm{dG})-\operatorname{poly}(\mathrm{dC})$ or a poly $(\mathrm{dC})-\operatorname{poly}(\mathrm{dG})-\operatorname{poly}(\mathrm{dC})$ triple helix in a supercoiled plasmid, depending on the presence or absence of $\mathrm{Mg}^{2+}$, respectively ${ }^{3}$. The $+\mathrm{Mg}^{2+}$ triplex forms stably in neutral or slightly basic buffers, whereas formation of the $-\mathrm{Mg}^{2+}$ triplex is enhanced by low $\mathrm{pH}$. The formation of dG-dG-dC (ref. 4), A-A-U (ref. 5) and 5'-TGGGGAGGGGTGGGGAGGGGTGGGGAAGG-3' purine-purine-pyrimidine (ref. 6) colinear triplexes under similar buffer conditions have also been reported. The base triplets predicted to occur with these triplexes have been observed in yeast transfer RNA ${ }^{\text {? }}$. Therefore our error does not alter our interpretation that the $\mathrm{T} 7$ transcript stabilizes an intramolecular DNA triplex.

Department of Microbiology,

University of Alabama at

Birmingham,

Birmingham, Alabama 35294, USA

\section{Boehringer Ingelheim}

Pharmaceuticals, Inc.,

90 East Ridge, PO Box 368.

Ridgefield, Connecticut 06877, USA

1. Reaban, M. E. \& Griffin, J. A. Nature 348, 342-344 (1990). 2. Collier, D. A., Griffin, J. A. \& Wells, R. D. J. biol. Chem. 263.
$7397-7405$ (1988).

3. Kohwi, Y. \& Kohwi. Shigematsu, T. Proc. natn. Acad. SCl. U.S.A. 85, 3781-3785 (1988)

4. Marck, T.. Thiele, D., Schneider, C. \& Guschibauer, W. Nucleic Acids Res. 5, 1979-1996 (1978).

5. Broitman. S. L., Im, D. D. \& Fresco, J. R. Proc. natn. Acad. Sct U.S.A. 84, 5120-5124 (1987)

U.S.A. 84, 5120-5124 (1987).
6. Cooney, M., Czernuszewicz, G., Postel, E. H., Flint, S. J. \& Hogan, M. E. Science 241, 456-459 (1988).

7. Cantor. C. R. \& RSchimme!, P. R. Biophysical Chemistry, Part 1: The Conformation of Biological Macromolecules (Freeman, San Francisco, 1980).

\section{Whales and the military}

SIR - Several live mass strandings of Goosebeaked whales (Ziphius cavirostris) have recently been reported ${ }^{\prime}$ on the coasts of Fuerteventura, Canary Islands. In February 1985,12 were stranded in the southern coast accompanied by a Gervais' beaked whale (Mesoplodon europaeus); in June 1986, four more were stranded alive on the northern coast, again with a single $M$. europaeus; in November 1988, three Ziphius and a single northern bottle-nosed whale (Hyperoodon ampullatus) were stranded on the southeast side (on the same date two pygmy sperm whales (Kogia breviceps) were stranded on है the neighbouring island of $\frac{3}{z}$ Lanzarote). Military manoeuvres were observed at sea close to the stranding sites in February 1985 and November 1988 (ref. 1). fitherto unre- open bars, other species; asterisks, live strandings; black ported mixed-species live arrowheads, military activity.

mass stranding occurred on Fuerteventura in October 1989; three M. europaeus came ashore with two $M$. densirostris (de Blainville's dense-beaked whale) and many Ziphius. In total, about 24 animals are estimated to have stranded by M. Pizarro, R. Vonk and V. Martin. Again, the stranding occurred when naval vessels were clearly visible out to sea. Local people have only been aware of such military manoeuvres three times since 1985; on each occasion mass live strandings have occurred. No pathological examinations were conducted on any of the stranded animals but there were no apparent abnormalities or wounds. All the stranded animals soon died.

Strandings of $M$. europaeus on the east side of the Atlantic are very rare. Before the strandings in the Canaries only two others had been reported ${ }^{2}$. There are also only a few reports of multiple deaths of Ziphius outside the Canaries'; first, off Venezuela, when four decomposed bodies washed ashore on an island (the recorder considered that an underwater explosion, related to naval manoeuvres, might be responsible; second, when the bodies of three Ziphius and a striped dolphin (Stenella coeruleoalba) came ashore on the coast of Corsica with bul-

let holes in them; and third, a mass stranding, about which no further details are known, that occurred on the east coast of the United States. Two further small strandings are also known from the Galapagos and Puerto Rico.

Details of the general pattern of strandings in the Canaries from 1981 to 1987 have been noted by Vonk and Martin, and are presented with the mass strandings of 1988 and 1989 in the figure. The island of Fuerteventura is the closest of the Canary Islands to the African mainland. It is also the main island from which local people fish (off the east side) for squid. The sea between Africa and the island may, therefore, be an important feeding ground for toothed whales. (Mesoplodon stomachs have been found to contain hundreds of squid beaks.)

Reports of military interactions with cetaceans are rare, although sperm whales in the southeast Caribbean became atypically silent and then scattered when exposed to intense underwater, local, military sonar signalling, apparently from submarines ${ }^{3}$.

Naval manoeuvres off Fuerteventura may have stimulated an invasion of the island by ships coming towards the east coast through the whales' feeding grounds. This could have driven the whales shorewards and caused them to strand. Very little is known about the biology of Ziphius, so the reason for the unusual strandings can only be the subject of speculation.

School of Biological Sciences,

M. P. SIMMONDS

Queen Mary and Westfield College,

University of London,

Mile End Road, London E1 4NS, UK

Department of Biology,

L. F. LOPEZ-JURADO

Veterinary Faculty,

University of Las Palmas,

Francisco Inglott Artiles 12,

35016 Las Palmas de Gran Canaria, Spain

1. Vonk, R. and Martin V. 1989. Proc. 3rd Ann. Conf. E.C.S. 7377 (1989).

2. Mead, J. G. Handbook of Marine Mammals (eds Ridgeway, S. H. \& Harrison, R. J.) (Academic, London 1989).

3. Watkins, W. A., Moore, K. E. \& Tyack, P. Cetology 49; 1-15 (1985). 